\title{
High-protein goat's milk diet identified through newborn screening: clinical warning of a potentially dangerous dietetic practice
}

\author{
Evelina Maines 1,*, Giorgia Gugelmo ${ }^{1}$, Elisa Tadiotto ${ }^{2}$, Angelo Pietrobelli², \\ Natascia Campostrini ${ }^{1}$, Andrea Pasini ${ }^{1}$, Florina lon-Popa ${ }^{1}$, Monica Vincenzi ${ }^{1}$, \\ Francesca Teofoli ${ }^{1}$, Marta Camilot ${ }^{1}$ and Andrea Bordugo ${ }^{1}$ \\ 'Department of Pediatrics, Regional Centre for Newborn Screening, Diagnosis and Treatment of Inherited Metabolic \\ Diseases and Congenital Endocrine Diseases, Azienda Ospedaliera Universitaria Integrata, Piazzale L.A. Scuro 10, \\ 37134 Verona, Italy: ${ }^{2}$ Pediatric Clinic, 'Giambattista Rossi' Hospital, University of Verona, Verona, Italy
}

Submitted 6 May 2017: Final revision received 4 June 2017: Accepted 8 June 2017: First published online 24 July 2017

\begin{abstract}
Objective: Breast-feeding is an unequalled way of providing optimal food for infants' healthy growth and development and the WHO recommends that infants should be exclusively breast-fed for the first 6 months of life. For mothers who are unable to breast-feed or who decide not to, infant formulas are the safest alternative. Despite recommendations, it is possible that parents make potentially harmful nutritional choices for their children because of cultural beliefs or misinformation on infant nutrition. We describe a possible health risk of not breast-feeding, highlighting a potentially dangerous dietetic practice.

Design/Setting/Subjects: We report the case of a newborn who was fed with undiluted goat's milk because her mother could not breast-feed and was not aware of infant formulas.

Results: The dietary mistake was detected because of a positive expanded newborn screening result, characterized by severe hypertyrosinaemia with high methionine and phenylalanine levels, a pattern suggestive of severe liver impairment. The pattern of plasma amino acids was related to a goat's milk diet, because of its very different composition compared with human milk and infant formula.

Conclusions: Our experience demonstrates that, when breast-feeding is not possible or is not exclusive, infants may be at risk of dangerous nutritional practices, including diets with very high protein content, such as a goat's milk diet. Families of not breast-fed infants may need appropriate advice on safe alternatives for infant nutrition to avoid the risks of inappropriate diets.
\end{abstract}

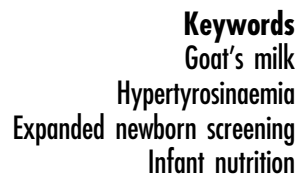

Keywords (a) Infant nutrition
Nutrition in early childhood affects health and disease risk in later life ${ }^{(1)}$. In particular, protein intake, both in quantity and in quality, during the first 2 years of life is recognized as having an important role in growth, neurodevelopment and long-term health ${ }^{(2)}$.

Breast-feeding is an unequalled way of providing optimal food for infants' healthy growth and development and the WHO recommends that infants should be exclusively breast-fed for the first 6 months of life. For mothers who are unable to breast-feed or who decide not to, infant formulas are a safe alternative ${ }^{(3,4)}$. Despite recommendations, it is possible that parents make wrong nutritional choices for their children because of cultural beliefs or misinformation on infant nutrition.
Goat's milk is not approved for use in infants ${ }^{(4)}$, because its protein and potassium load is about double and the chloride load four times the amount present in most infant formulas ${ }^{(5)}$. The consumption of undiluted goat's milk diets by infants has been associated with metabolic acidosis and severe electrolyte imbalances. Moreover, reports have also described associated morbidities such as acute stroke, megaloblastic anaemia, infections, haemolytic uremic syndrome and allergic reactions including lifethreatening anaphylactic shock ${ }^{(5-8)}$. Newborn screening (NBS) results close to those observed in patients affected by tyrosinaemia ${ }^{(5,7)}$, a disorder of the catabolic pathway of the amino acid tyrosine, or maple syrup urine disease ${ }^{(8)}$, a disorder affecting the metabolism of branched-chain 
amino acids, have also been reported in infants fed goat's milk.

We report the case of a newborn fed with undiluted goat's milk who was recalled for a positive NBS result, characterized by severe hypertyrosinaemia with high methionine and phenylalanine levels, a pattern indicative of severe liver impairment ${ }^{(9)}$.

\section{Case presentation}

Born at 40 weeks of gestational age, after an uneventful pregnancy, our patient had a birth weight of $2480 \mathrm{~g}$ (3rd percentile). In the first $24 \mathrm{~h}$ of life she presented with transient clotting abnormalities treated with plasma transfusion. The NBS performed at $36 \mathrm{~h}$ of life was not valid because of the transfusion and, in line with standard procedures, it was repeated at $9 \mathrm{~d}$ of life. At that time, the newborn was growing and feeding well with breast milk and was discharged.

NBS was also repeated at $14 \mathrm{~d}$ of life as a standard procedure for low birth weight and showed high tyrosine, phenylalanine and methionine levels (Fig. 1). In particular, tyrosine was greater than $1000 \mu \mathrm{mol} / \mathrm{l}$ (normal range: $46 \cdot 5-250 \mu \mathrm{mol} / \mathrm{l}$ ) on dried blood spot. Succinylacetone (SUAC), a specific marker of tyrosinaemia type 1, was normal.

After the confirmation of NBS results at $23 \mathrm{~d}$ of life, a severe liver disease was suspected and the newborn was recalled for examination and further investigation. At admission, clinical examination was normal. Initial testing results were consistent with moderate metabolic acidosis
( $\mathrm{HCO}_{3}^{-} 17 \mathrm{mmol} / \mathrm{l}$, base excess $7 \mathrm{mmol} / 1$, normal anion gap). Liver function values and electrolytes were within normal limits. Plasma tyrosine was above $2000 \mu \mathrm{mol} / \mathrm{l}$ (normal plasma value: 55-250 $\mu \mathrm{mol} / \mathrm{l}$ ), plasma phenylalanine and methionine were increased to $427 \mu \mathrm{mol} / \mathrm{l}$ (normal plasma value: $39-90 \mu \mathrm{mol} / \mathrm{l}$ ) and $328 \mu \mathrm{mol} / \mathrm{l}$ (normal plasma value: 11-40 $\mu \mathrm{mol} / \mathrm{l}$ ), respectively. Tyrosine, phenylalanine and methionine levels on dried blood spot were $2463 \mu \mathrm{mol} / \mathrm{l}$, $352 \mu \mathrm{mol} / 1$ and $357 \mu \mathrm{mol} / 1$, respectively.

Organic acids analysis on urine confirmed the absence of SUAC. The patient was started on a tyrosine- and phenylalanine-free formula feed. The acidosis was quickly corrected and did not recur. Blood tyrosine, phenylalanine and methionine normalized in $48 \mathrm{~h}$.

Dietary history revealed that, after the first discharge, the patient was fed undiluted goat's milk plus small volumes of breast milk as breast-feeding was considered not sufficient. The parents did not verify the lack of breast milk and did not search support of a paediatric service because they did not consider infant feeding a complex task. The parents, both of Romanian origin, had lived in Italy for a few months in a restricted community of Romanian people. The mother was a 20-year-old housewife and she was not able to speak Italian or English. The father was a 22-year-old farmer and he seemed to understand Italian. The father stated that they chose goat's milk in a superficial manner because they considered it digestible and suitable for infants.

We estimate that the patient has received three to four times more protein than is recommended (Table 1). Her parents were really surprised to know that goat's milk is potentially harmful for infants. They did not know that it

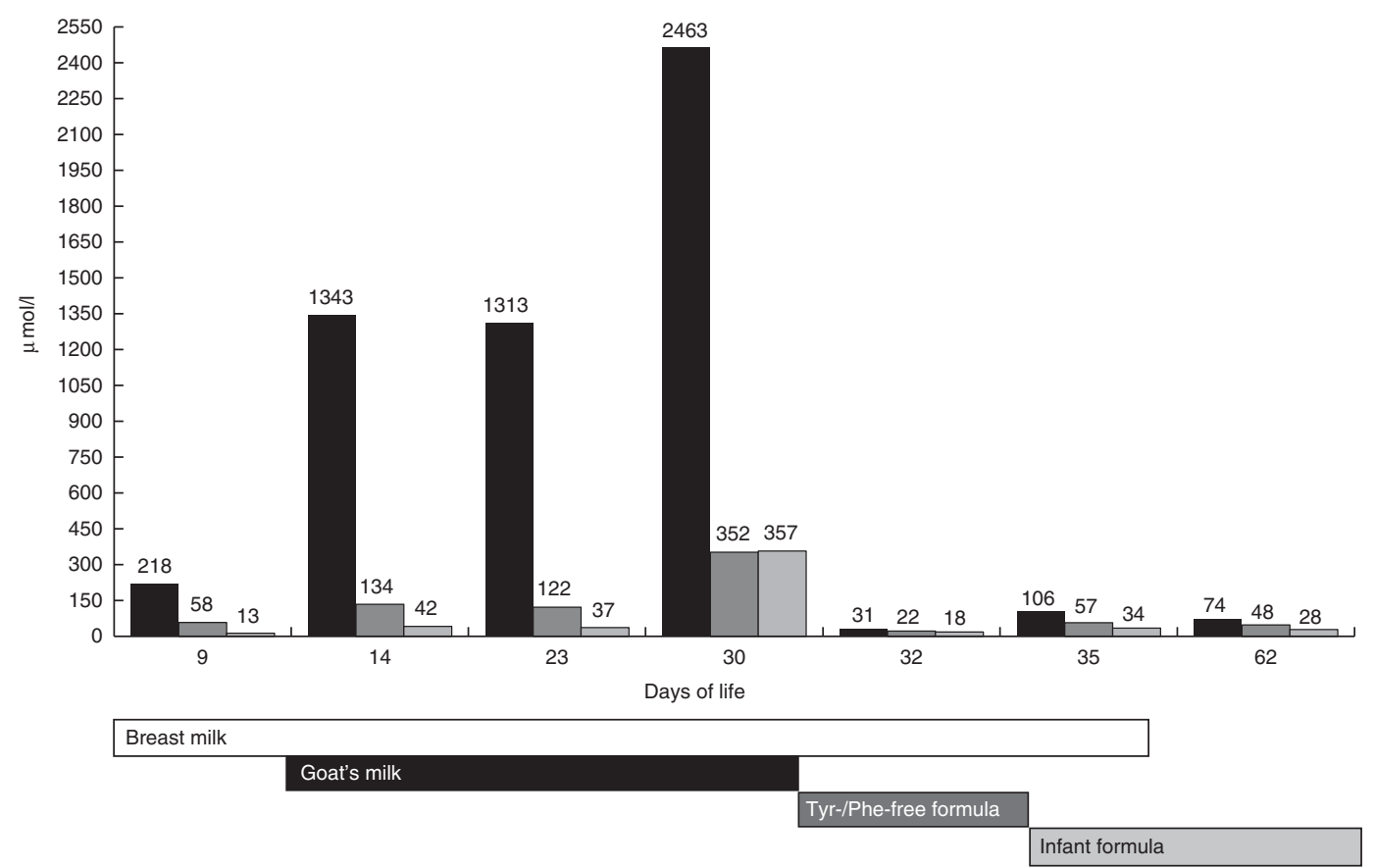

Fig. 1 Tyrosine (Tyr; $\square$ ), phenylalanine (Phe; $\square$ ) and methionine ( $\square$ ) levels on dried blood spots at the patient's main checks. Nutritional diets are also reported in relation to dried blood spot levels 
Table 1 Comparison of nutritional intake between our patient and a breast-fed or standard formula-fed newborn of same weight $(3.2 \mathrm{~kg})$ and fluid intake $(550 \mathrm{ml} / \mathrm{d})$. The source of nutritional information is reported in parentheses

\begin{tabular}{lccc}
\hline & $\begin{array}{c}\text { Goat's milk } \\
\left(\text { USDA }^{10}\right)\end{array}$ & $\begin{array}{c}\text { Standard infant formula 1 } \\
(\text { nutritional label })\end{array}$ & $\begin{array}{c}\text { Human breast milk } \\
\left(\text { USDA }^{10}\right)\end{array}$ \\
\hline Energy $(\mathrm{kcal} / \mathrm{kg})$ & 118 & 113 & 120 \\
Protein $(\mathrm{g} / \mathrm{kg})$ & $6 \cdot 1$ & $2 \cdot 2$ & $1 \cdot 8$ \\
Phenylalanine $(\mathrm{mg} / \mathrm{kg})$ & 266 & $96 \cdot 5$ & 79 \\
Tyrosine $(\mathrm{mg} / \mathrm{kg})$ & 308 & 95 & 91 \\
\hline
\end{tabular}

USDA, US Department of Agriculture.

*Professional nutrition facts of Infant formula Mellin 1. Data about the phenylalanine and tyrosine content are not available online.

has a very different composition compared with human milk and infant formula ${ }^{(10)}$.

After our evaluation, the infant was discharged and specific and precise feeding advice was given to the family. The patient is now 4 months old and she is fed with infant formula. She is gaining weight within a normal range and her development is normal.

\section{Discussion}

Health outcomes in developed countries differ substantially for infants who formula-feed compared with those who breast-feed. In fact, formula-fed infants face higher risks of infectious morbidity, childhood obesity and chronic disease ${ }^{(11)}$.

Our experience demonstrates that, when breast-feeding is not possible, infants may be also at risk of dangerous nutritional practices, such as inappropriate high-protein diets.

High-protein diets in infancy have an important effect on plasma amino acid levels, particularly tyrosine. This is demonstrated by the evidence that infant tyrosine levels have fallen dramatically in the last four decades because of concomitant increase in breast-feeding rates and reduction in the protein content of commercial infant formulas.

High tyrosine levels have been associated in the long term to intellectual deficits with variable degrees of developmental retardation, eye symptoms and skin lesions. Severe neurological manifestations, including microcephaly, seizures, tremors and behavioural difficulties, have been also described ${ }^{(5-8)}$.

At the time of evaluation our patient was clinically asymptomatic and only a mild metabolic acidosis was detected. It is difficult to predict what would have happened if the baby had continued to take goat's milk. If NBS had not been repeated during the high protein administration, it is possible that the inappropriate diet of our patient would not have been precociously detected.

Since NBS is usually performed between 36 and $48 \mathrm{~h}$ of life when the baby is still in hospital, NBS programmes may not identify high-protein diets unless specific followups are requested. Moreover, NBS is performed in only a few countries.

Our case highlights that, when breast-feeding is not possible or is not exclusive, infants may be at risk of potentially harmful diets. To reduce the risks of not breastfeeding, it is important to promote breast-feeding support groups for referral of mothers to them on discharge from the hospital. Infant feeding should be assessed by hospital and community paediatric services at every clinical evaluation, not only for promoting breast-feeding, but also for educating and counselling families about the risks associated with alternative diets. Particular attention may be required to families belonging to a small foreign community. When breast-feeding is not possible or is not exclusive, families may need appropriate advice on safe alternatives for infant nutrition to avoid dangerous nutritional practices.

\section{Acknowledgements}

Acknowledgements: The authors are grateful to Mr Giorgio Mazzoleni and Mrs Helena Andersson for editing the English version of the manuscript. Financial support: This research received no specific grant from any funding agency in the public, commercial or not-for-profit sectors. Conflict of interest: The authors declare that they have no competing interests. Authorship: E.M. conceived the work and wrote the draft; G.G. performed dietetic evaluation; E.T. and A. Pietrobelli revised the manuscript critically for important intellectual content; N.C., A. Pasini, F.I.-P., M.V., F.T. and M.C. performed expanded NBS and amino acids analysis; A.B. ensured the accuracy of the data and revised the manuscript critically. Ethics of human subject participation: All procedures were performed in compliance with the Declaration of Helsinki.

\section{References}

1. Lucas A (1998) Programming by early nutrition: an experimental approach. J Nutr 128, 401-416.

2. Michaelsen KF \& Greer FR (2014) Protein need early in life and long-term health. Am J Clin Nutr 99, Suppl. 3, $718-722$.

3. World Health Organization (2007) Protein and Amino Acid Requirements in Human Nutrition. Report of a Joint WHO/ FAO/UNU Expert Consultation. WHO Technical Report Series no. 935. Geneva: WHO.

4. Commission of the European Communities (2006) Commission Directive 2006/141/EC of 22 December 2006 on infant formulae and follow-on formulae and amending 
Directive 1999/21/EC. Official Journal of the European Union 30.12.2006, L401/1-L401/33; available at http:// eur-lex.europa.eu/eli/dir/2006/141/oj

5. Hendriksz CJ \& Walter JH (2004) Feeding infants with undiluted goat's milk can mimic tyrosinaemia type 1. Acta Poediatr 93, 552-553.

6. Basnet S, Schneider M, Gazit A et al. (2010) Fresh goat's milk for infants: myths and realities: a review. Pediatrics 125, e973-e977.

7. Techakittiroj C, Cunningham A, Hooper PF et al. (2005) High protein diet mimics hypertyrosinemia in newborn infants. J Pediatr 146, 281-282.
8. Chapman KA, Ganesh J \& Ficicioglu C (2008) A falsepositive newborn screening result: goat's milk acidopathy. Pediatrics 122, 210-211.

9. Morgan MY, Marshall AW, Milsom JP et al. (1982) Plasma amino-acid patterns in liver disease. Gut 23, Suppl. 5, 362-370.

10. US Department of Agriculture, Agricultural Research Service, Nutrient Data Laboratory (2017) USDA Food Composition Databases. https://ndb.nal.usda.gov/ndb/ search/list

11. Stuebe A (2009) The risks of not breastfeeding for mothers and infants. Rev Obstet Gynecol 2, 222-231. 